Open Access

\title{
Correction to: a flexible distribution class for count data
}

Kimberly F. Sellers ${ }^{1 *}$, Andrew W. Swift ${ }^{2}$ and Kimberly S. Weems ${ }^{3}$

* Correspondence:

kfs7@georgetown.edu

${ }^{1}$ Department of Mathematics and

Statistics, Georgetown University,

306 St. Mary's Hall, Washington, DC 20057, USA

\section{Correction}

Following publication of the original article (Sellers et al., 2017), the authors reported that the typesetters had misinterpreted some of the edits included in their proof corrections, namely instances of "sp" to denote that an extra space was required.

The original article has been corrected.

\section{Author details}

'Department of Mathematics and Statistics, Georgetown University, 306 St. Mary's Hall, Washington, DC 20057, USA. 2Department of Mathematics, University of Nebraska - Omaha, 6001 Dodge Street, Omaha, NE 68182, USA.

${ }^{3}$ Department of Mathematics and Physics, North Carolina Central University, 2211 Mary M. Townes Science Building, 1801 Fayetteville Street, Durham, NC 27707, USA.

Received: 11 October 2017 Accepted: 11 October 2017

Published online: 16 October 2017

\section{Reference}

Sellers, K.F., Swift, A.W., Weems, K.S.: A flexible distribution class for count data. J. Stat. Distrib. Appl. 4, 22 (2017). DOI 10.1186/s40488-017-0077-0 